\title{
Interaction between Feedback Types of Interactive Videos Used in Flipped Classroom and Learning Styles of Talented Students in Developing Personal Knowledge Management Skills and Achievement
}

\author{
Usama M. Ibrahem, \\ Hail University- KSA- \\ Suze Canal University- \\ Ismailia, Egypt
}

\author{
Hisham Y. Alaraby, \\ Hail University- KSA \\ Suze Canal University-Egypt, \\ Ismailia, Egypt
}

\author{
Hanan M. Diab \\ Hail University- KSA \\ Hail University, 81481, \\ Hail, KSA
}

\begin{abstract}
This study aims at exploring Interactive Videos (IV) used in Flipped Classroom (FC) and their feedback types and Learning Styles (LS) of Talented Students (TS) in developing Personal Knowledge Management Skills (PKMS) and achievement. The study was conducted on 51 STS from Hail Gifted Care Center in KSA, where they divided into four experimental groups depending on their LS and IV's feedback. The study occurred during the first term of the academic year 20192020. In the FC based on IV, no statistical differences between the TF and $\mathrm{AF}$ were present in interactive videos on the achievement or PKMS for talented students. Also, no statistical differences between the LS (convergentdistant) in the total PKMS and achievement for STS were present when applying interactive videos-based flipped classrooms, same for statistical interaction effects between the $\mathbf{T F}-\mathbf{A F}$, save for some interaction effects in some knowledge management skills (conveying, analysis, organizing). Future research could address the diminishing motivation incurred with the interactive videos-based flipped classrooms. Specifically, how to design IV-based FCs with feedback types that encourage students to develop KPMS
\end{abstract}

Keywords - Feedback; Interactive Videos (IV); Flipped Classroom (FC); Learning Styles (LS); Science-Talented Students (STS); Personal Knowledge Management Skills (PKMS); Achievement.

\section{INTRODUCTION}

$\mathrm{D}$ espite the many efforts to support gifted students, they do not receive adequate services for their learning needs in the regular classroom [1]. We may know what works for gifted education in more traditional settings, yet the lack of research on online learning means knowledge about the efficacy of online learning for the gifted is impaired [2].

Many talented students miss out on their full potential unless the curriculum responds to their needs and stimulates their thinking. Several studies on gifted students point to a connection between learning styles and classroom performance [3]. Talented students' LS differ from general population students, where talented students prefer instructional methods emphasizing independence (independent study, discussion) [4]. Students must be encouraged to "stretch" their LS to be empowered in a variety of learning situations [5]. LS plays contributed to classroom performance and the way gifted middle school students respond to their classroom [6];[1]. Without appropriately stimulating environments, gifted students become frustrated, bored, and unmotivated [1]. Although technology by itself may not be motivating, the opportunities that technology presents and motivation for TS seem to correlate. When technology aligns with authentic or "real-world" applications, motivation can surge [7];[8]. Technology can effectively accelerate coursework to exceptional middle school students, effecting costeffectiveness, parent and student satisfaction, and individualized talent-focused work pace [2].

Educators worldwide are promoting a blendedlearning environment that combines technology 
with traditional teaching. Flipped classrooms follow the concept of a blended-learning strategy that has recently gained popularity [9]. In this pedagogical approach, the students work independently outside the classroom to study basic concepts through different methods like online lectures, videos, and articles. The learning is self-paced; the classroom time is then used for the application of the learned material in the class. The students engage in activities focusing on the development of skills of concepts application and factual knowledge they have acquired earlier [10]; [11]; [12].

Governments encourage the use of video-based FC by funding schools, enabling the implementation of FC [13]. Students suggested that teacher's footage and surprise questions should be included in interactive videos [14].

Several advantages of FC were reported as the: increased understanding, the development of critical and higher-level thinking, self-regulated learning, collaborative work, and face-to-face interaction with the lecturer [15]; [16]; [17]; [18]; [11]; [19].

Interactive videos are a recent addition to flipped learning, allowing students to actively engage with the teaching material rather than passively watching it [20]. These videos contain embedded interactive activities, e.g., quizzes and open questions, to somehow engage students [21]. Video-based FC instruction can strengthen learning motivation [9:387], thus providing theoretically sound deep learning for students of different abilities [9:388]. Interactive videos raise the motivation and intrigue learners, availing effective learning. Interactive videos perpetually prompt the learner to interact with the program during the presentation with the possibility of providing feedback actively [22]; [23].

The benefits of video-based FC instruction assume that all learners are motivated and selfregulated to complete the assigned learning tasks outside class time. [24].

Providing gifted learners with appropriate choices for accelerated coursework in their area of talent or interest in this type of blended-learning model can help them meet their potential for academic achievement [2].

To succeed in today's information-oriented environment, knowledge uses the need to exercise information literacy skills [25]. This increasing shift towards the adoption of personal knowledge skills. Ineffective PKM practices are mostly caused by the lack of correct technology-associated skills; individuals can only exercise PKM optimally with effective technology-related skills [26]; [27]. one key purpose of PKM is to provide a framework for individuals to manage and integrate new information and enrich their knowledge database effectively, thus empowering individuals to easily apply their knowledge to handle new and old problems and learn from new experiences. It is one of the needs of the gifted students that many types of research had mentioned [28].

PKMS' importance has been addressed by many researchers [29]; [30]. It helps individuals with knowledge creation, management, and application. It is not easy helping students to manage their knowledge efficiently, especially in online courses. The key issues are managing and supporting personal knowledge and information so that it is accessible, meaningful and valuable to the individual; maintaining networks, contacts, and communities; making life easier and more enjoyable; and exploiting personal capital [31]; [30]. Technology-enhanced individual prowess is a critical part of PKM, and such technology will help users to classify information and archive interactions, emails, and other items to easily locate them [26:334]; [32].

\section{Literature Review}

Literature suggests that while blended-learning programs are a growing segment of online learning in K-12 schools that can facilitate a wider variety of benefits for extending gifted programming, very little has been documented about the role and effectiveness of blended-learning in a giftedstudents classroom, and none of this literature is empirical [2:295].

Gifted education in KSA has been under the leadership of two main institutions: Mawhiba and the Ministry of Education. Many of the enrichment services that are offered in schools and summer enrichment programs in KSA are based on the Oasis Enrichment Model. Due to the nature of the education system in KSA, the administration of the 
model mostly employed a pullout approach, where gifted students are gathered together outside the mainstream classes to join systematic enrichment programs either during the academic year or during the summer vacation [33].

\section{Flipped Classroom}

A FC approach comprises two distinct parts: direct online instruction at the students' own time and pace and interactive group learning activities in scheduled classes [34]; [35]. Many of FC's underlying principles and techniques (active learning, studentcentered instruction, self-directed inquiry, peer instruction, and constructivist learning theory) were thoroughly researched and used successfully for decades [36]; [37]. Students recognized that FCs were more efficient than traditional approaches [16:1466]; [17:80]; [18]; [19].

Interactive Videos-Based FC Advantages

Interactive components, e.g., quizzes or online exercises, should be included when creating online videos because interactive videos can be enriched, or "annotated", with other media types, i.e., texts, pictures, audios, and videos [38], but interactive videos are usually snippets of animations [39]. Videos have become crucial in modern educational systems [40]. IVs was described as one of the most exciting types of media that combines the power of moving images, story, depth, and richness of information enriched with interactivity [41]. It combines the capabilities and characteristics of video and computer within the learner's control, whether in operation, access to learning resources, or choosing the required sequences from video, audio, texts, drawings, or pictures [42].

Interactive videos are defined as video programs divided into small parts consisting of kinematic sequences and fixed frames, questions and lists, and the learner's responses via the computer, which are the determinant of the number of video clip sequences; IVs are a combination of video and computer technology where a computer is used to interact with information to provide an interactive environment enabling the learner to control video [43]; [44]; [45].

IV-based FC has been claimed to show the following advantages [9]; [16]; [11]: (1) Online assessment helps teachers determine students' level of understanding before attendance; teachers can appropriate to that level, improving class discussion and exercises. (2) It helps deal with individual differences in learning; weak learners can replay the videos and redo the assessments per their learning needs until they can fully understand the contents. (3) Post-viewing reflective activities can be developed for formative assessment purposes enabling the lecturer to ensure the following workshop activities meet the specific learning needs of the students. (4) More of the learning responsibility is transferred to the student. (5) It is flexible to cover a wider range of materials.

According to research findings IV could be used in FC to engage, motivate, allows full attention, and improve their learning, There are many tools for creating IV [46];[47];[48]. Free educational website for educators and learners (TED-Ed platform, Play posit platform).

\section{Feedback in $I V$}

IVs are related to various types of interaction. Feedback can be provided to the learner, ensuring they are on track and achieve the proficiency required. Feedback is the information sent to the learner to modify thinking or behavior and improve learning [49]. Feedback, functionally, is a twoparameter evaluation process: the goal and the level to be reached.

Feedback can be recognized as the process of providing the learner with information about his response in an organized and continuous manner to help them with the necessary amends for the correct response [50]; [51].

Previous studies' showed that classifications of feedback types can be summarized in figure 1 . [52]; [53]; [54]. 


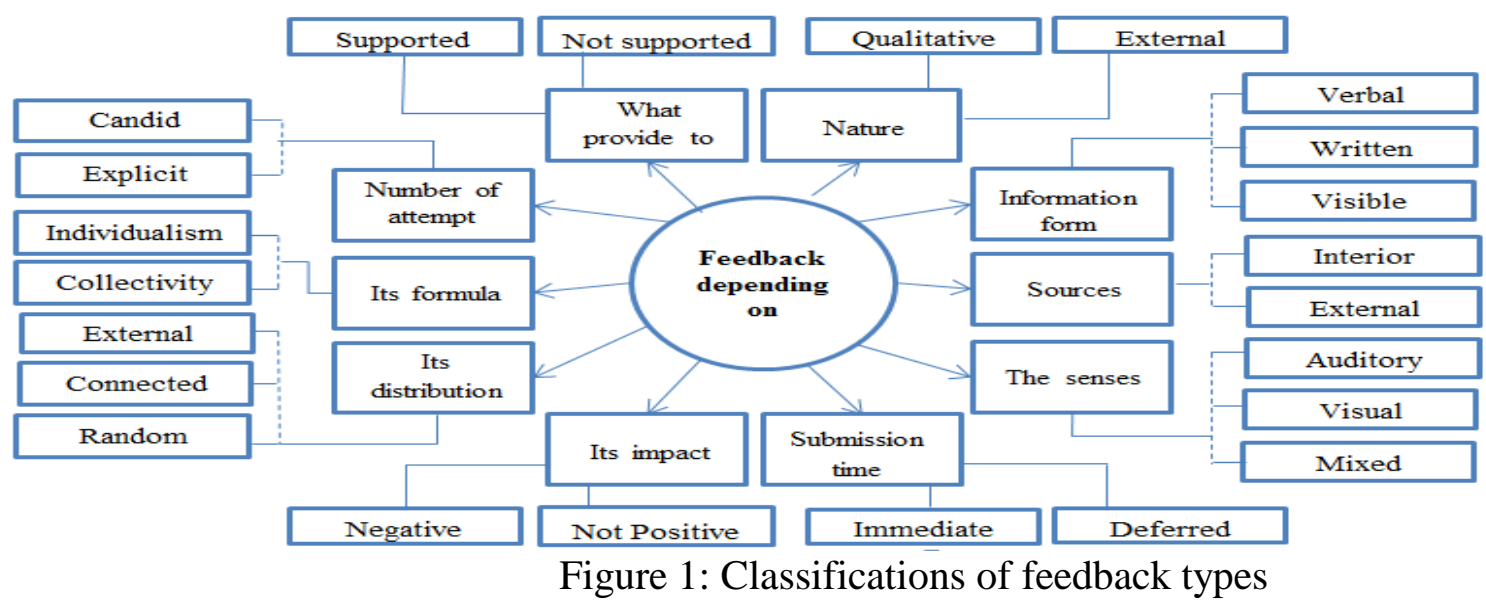

Studies confirmed that students with a specific learning style may respond more positively to different personally preferred types of feedback, further developing their [52].

\section{FC for $G T$}

The concept of giftedness in the Oasis Enrichment Model is viewed as a composite of the cognitive, personal, and social aptitudes and skills that enable the individual to excel in one or more fields of interest as compared to their peers. This concept is sufficiently flexible and expandable to incorporate the elements that contribute to excellence in a given domain, such as heritable innate abilities (intelligence), cognitive abilities, personal and social traits (including motivation), and the cultural, knowledge-related, and experiential opportunities that an individual may be involved in.

The perceptions and experiences of gifted students and their teachers to better understand how online learning environments can meet the needs of ST. were examined [55], It was found that the online format was conducive to a more individualized and differentiated learning experience than the regular face-to-face setting: "Students can work at a pace consistent with their rate of learning, have more time to reflect, feel more in control of the learning process, and engage in more self-directed and independent learning"

Alternatively, some advantages of flipped classrooms identified as: developing critical and higher-level thinking, collaborative work, schedule flexibility, and ability to review or pause lecture materials when needed. All of this is aligns with what is recommended by talented studies, where talented students need to lead their learning and determine their speed in learning, attention to higher skills, and management of personal knowledge and their experiences [16];[18];[19].

Relationship between LS and TS

Learning styles influence how students respond to classroom performance [3]. Learning styles was assisted in terms of how the learner process absorb, and retain information [56]. And was defined as a set of behaviors defining the individual's preferred and relatively constant method that makes them more efficient and effective in handling information [57].

Talented students tend to be independent and aware of their own needs, feelings, and attributes distinctly from others' [58]. Some studies pointed out that learning styles may not differ between high- and low-achieving students [58]; [59]. Excelling middle school students prefer visual, auditory, verbal, logical, and independent LS, while kinesthetic and interpersonal LS did not have significant influences on scores [60]. Similarly, students using independent, analytical, and systematic LS are more likely to perform better [13].

\section{LS Measurement}

Kolb identified four LS: diverging (concrete experience and reflective observation), assimilating (abstract conceptualization and reflective observation), converging (abstract conceptualization and active experimentation), and accommodating (concrete experience and active experimentation) using its LS inventory scores [62]. There is no strong correlation between participants' LS preferences and their achievement scores; the 
learning styles showed no association with students' overall achievement [5].

All versions of the LS scale have had the same format: a short questionnaire (nine items for LS, and 12 items for subsequent versions) where respondents to rank four-sentence endings that correspond to the four learning styles.

\section{Importance of PKMS for TS}

PKMS are skills that lead enhance cognition, communication, collaboration, creativity, problemsolving, lifelong learning, social networking, and leadership to improve the effectiveness, productivity, and innovation of individuals [63];[64]. The most essential type of skills of information, ideas, and knowledge elements are accessing, evaluating, organizing, analyzing, conveying, collaborating, and securing information and ideas [65]. PKMS improve students' cooperation, collaboration, and connection among similarinterest individuals in data and information processing into knowledge [66]. That is what the talented needs. There is an effective relationship between the utilization of technology and increasing PKMS [67].

These skills are time control; workplace wellness; speedy reading, notation, and research; document structuring; information design; target writing; processing infrastructure; and filtering techniques. Also, a set of strategies to help students manage their PKMS in online courses using web tools: socialization, externalization-, combination, and internalization proposed by [68].

Seven PKM skills were set as: retrieving; evaluating/assessing; organizing; analyzing; presenting; securing; and collaborating. Studies highlight the importance of PKMS in improving individual performance, enhancing individuals' personal, organizational and social environmental effectiveness, and developing abilities' selfawareness [68];[69];[70].

\section{Search Problem}

More than $70 \%$ of gifted students' teachers responded that their students were not challenged or given a chance to further develop in their classrooms. Talented students need advanced programs in many cases because the regular education program is not yet ready to meet their academic needs [71];[6]. Besides, science-talented students often get bored in passive learningtraditional lectures [23]. Previous studies of FC yielded promising results for various academic outcomes including enhancement of subject-based performance, language acquisition, critical thinking, and information literacy [72]; [73]; [74];[75];[76];[77];[78];[11]. Most interactive videosbased flipped classrooms exhibited effectiveness in developing some skills and increasing cognitive achievement [79]; [80]. Also, research studies indicate that science-talented students have maintained LS preferences that distinguish them from other students [59]. Therefore, a diverse approaches is required to cater to ST.

Students in the $21^{\text {st }}$ Century require soft skills and knowledge, preferably occurring in authentic learning situations and include greater collaboration, communication, problem-solving, and critical thinking [81]. There has been relatively little discussion about using PKMS and tools in the learning process [67]; [68]. Studies highlight the importance of PKMS in improving individual performance and effectiveness in personal, organizational, and social environments and developing self-awareness of their limits and abilities[66];[67];[70]; [81].

Currently, literature did not examine how the feedback of IV-based FC instruction with LS influences PKMS and achievement for STS. So, the research problem is determined without considering talented students' LS as one of the important drivers in educational design, besides the need to study some types of feedback appropriate to the proposed designs for developing PKMS and achievement for science-talented students.

\section{Questions}

(1) What is the effect of the difference between the (text and auditory) feedback in the IV on the Personal Knowledge Management Skills for science-talented students?

(2) What is the effect of the difference between the (text and auditory) feedback in the IV on the achievement for science-talented students?

(3) What is the effect of the difference between the LS (convergent- divergent) in IV on the Personal Knowledge Management Skills for science-talented students? 
(4) What is the effect of the difference between the LS (convergent- divergent) in IV on the achievement of science-talented students?

(5) What is the effect of the interaction between the (text and auditory) feedback in the IV and the LS (convergent- divergent) among sciencetalented students on Personal Knowledge Management Skills?

(6) What is the effect of the interaction between the (text and auditory) feedback in the IV and the LS (convergent- divergent) among sciencetalented students on achievement?

\section{Method}

- Research Model: This study was designed in the exploratory research method.

\section{- Participants}

The study was conducted on sciencetalented students in the G8 of middle school from the Hail Gifted Care Center. Students had to pass a measure of mental abilities testing at the KSA level and within the best 5\% with an academic level exceeding $90 \%$ in their schools.

\section{- Data Collection Tools}

An objective achievement test in the plant reproduction unit of science, The PKMS Scale, was prepared by Dorothy (2010) and translated by [82]. Assessment of LS was conducted using Kolb's LSI.

\section{Implementation}

- Variables: The research dealt with three types of variables: independent variables (feedback (audio/ text) with the IV), classification variable (convergent and distant LS), and dependent variable (achievement - PKMS).

- Design: This study employed a descriptiveanalytical method to analyze previous studies and a quasi-experimental transversal comparison of equivalent groups design to identify the effect of the interaction of independent and taxonomic variables on dependent variables as explained in table 1:

Table (1) Experimental design for research

\begin{tabular}{|c|c|c|c|c|}
\hline Experimental & Pre-Test & Treatment & Feedback & Post Test \\
\hline Group 1 & \multirow{4}{*}{$\begin{array}{c}\text { Achievement } \\
\text { Test }\end{array}$} & \multirow[t]{2}{*}{ FC based on IV for divergent } & $\mathrm{IV}-\mathrm{AF}$ & \multirow{4}{*}{$\begin{array}{c}\text { Achievement } \\
\text { Test + PKMS } \\
\text { scale }\end{array}$} \\
\hline Group 2 & & & IV - TF & \\
\hline Group 3 & & \multirow[t]{2}{*}{ FC based on IV for converging } & $\mathrm{IV}-\mathrm{AF}$ & \\
\hline Group 4 & & & $\mathrm{IV}-\mathrm{TF}$ & \\
\hline
\end{tabular}

(Usama, 2018) the model was adopted for the

Procedure

- Designing an FC Environment Based on IV: design of the FC based on the IV format (2): 


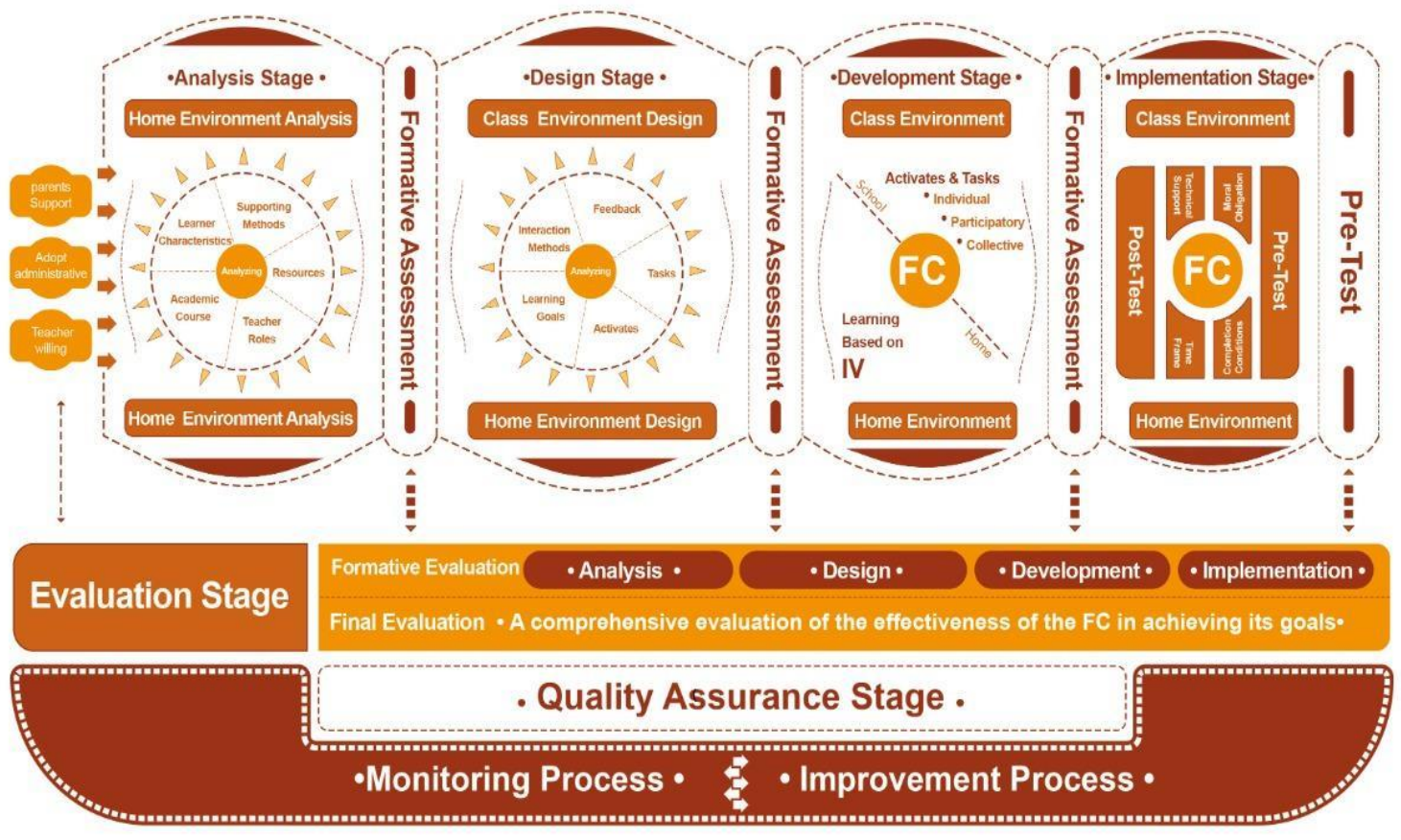

Figure 2: Educational design model for the FC

The analysis stage included the following:

- Problem analysis and needs assessment: The problem was identified as science-talented students' lacking personal skills and their educational needs were the need for a set of skills and knowledge developing their PKMS and achievement. 


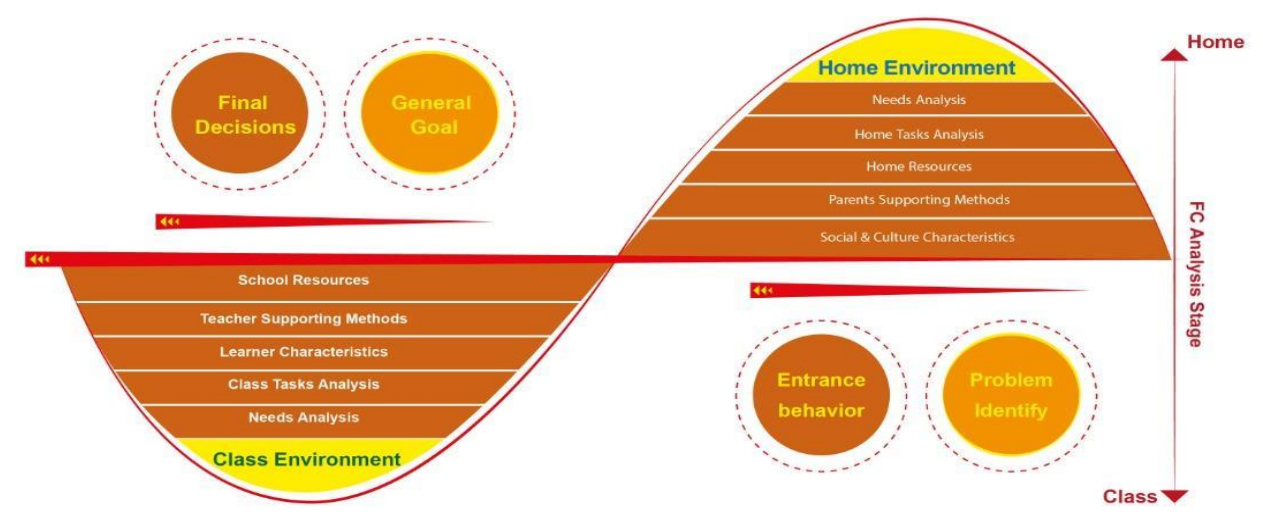

Figure 3: An analysis stage of the FC

First, this step ended with the formulation of the general goal of "Developing PKMS and achievement among STS", in light of the adoption of the list of PKMS [82].

- Analysis of educational tasks: set general objectives and analyze educational tasks branching into sub-procedures in the plant reproduction unit. The form and number of tasks that STS will perform in the classroom and those at home were determined.

- Learners' characteristics analysis: STS in G8 science educational challenges were the lack of PKMS-related information and skills. They were grouped into four experimental groups suited to divergence and convergence learning styles.

- Analysis of resources in the educational environment: The educational resources and resources available to STS, which were used to ensure the presence of a smart device or a computer with each student at home.
2- Second, the design stage: The formulation of the educational program design was planned for the $\mathrm{FC}$, and the stage contained the processes shown in figure 4 as follows:

- Formulating learning objectives: The objectives of the IV-FC were determined in light of a list of 40 goals.

- Organizing the content and following up its presentation: The plant reproductive unit content elements that can achieve the required objectives were identified.

- Defining activities and assignments: The activities and assignments presented in the FC and the IV content were identified by the two types of auditory feedback \& text feedback.

- Designing an education strategy: Learnercentered learning strategies were used to stimulate learning by drawing attention and setting goals associated with each skill.

- Determination of evaluation methods (tests and assignments for separation) and feedback methods for e-content (e-tests, eactivities, and assignments). 


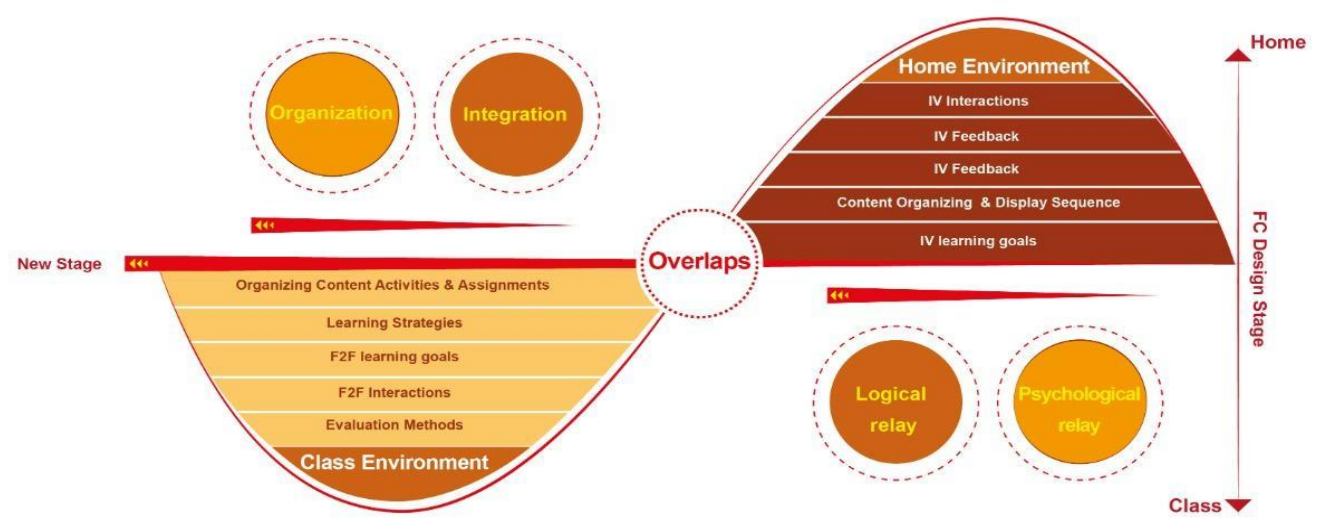

Figure 4: The design stage for the FC

The content was determined to achieve educational goals.

- The process of identifying meeting points

- Defining methods of presenting the content: The most appropriate (traditional/electronic) presentation method was chosen, and the content was reformulated into adaptive activities suiting to STSs' needs and facilitating the transition from face-to-face learning, class, and home learning.

- Feedback: Forms of auditory feedback \& text feedback were determined and presented to the learner, whether in the traditional classroom or during the IV.

- Interaction design and communication methods: The forms of interaction were identified (the learner's interaction within the classroom/home environment, the interaction of learners with each other/with the teacher, and the interaction of learners within the IV), and communication methods were identified within the learning environment (e-mail) with an emphasis on the importance of taking into account systemic work.

- Flowchart design: The learner's journey to the targeted learning outcomes were illustrated by streamlined flowcharts showing the arrangement of traditional or e-learning situations, the tribal requirements of each position, and how it relates to what follows or precedes it.
- Third, the development stage: It focused on the formation of multimedia elements presenting the content: traditional and e-texts, pictures, digital sounds, real and virtual samples and forms, fixed and animated graphics, and video clips (figure 5).

In light of production standards, the appropriate production incubation was chosen:

- Production incubation was based on the adoption of e-products (text, images, sounds, and video) and was used as it is.

- Partial Production Incubation for some eproducts was modified to suit the product with the needs.

- Total production incubation for some eproducts was developed according to the targeted learning needs.

The following IV build was done:

- Scenario Preparation: Per the skill list, behavioral goals, and content, an IV scenario content has been built and set up as follows: After designing the initial scenario, it was presented to specialists' review (goals, scientific terms, presentation and sequencing, the appropriate number of frames for content, appropriate forms of interaction, and feedback display method). Arbitrators confirmed the validity of the scenario for use by approximately $92 \%$, with the amendment of some language versions 
and the addition of some illustrative examples. Adjustments were made and the scenario was finalized.

Production of video footage: Videos were recorded via Snagit9. The clips were stored on the computer via the TV card. Then the clips were compressed. The audio was then dubbed on the video. The texts were written using Microsoft Office Word 2010, accounting for the compatibility between font and screen sizes and display area.
Adobe Audition CC7.0 CS5 was used for sound production and effects. Output was in mp3, Wav format. Adobe Premiere Pro CC 2016 was used to produce various video elements, whether for IV. Photoshop CC 7.0 Adobe was used for graphics and still images and image adjustments, basic template, and button designs. Output images and graphics were in .jpg, .png formats. Illustrator CC 2015 software was used for producing bitmap and linear images and handling graphics in ai, esp.

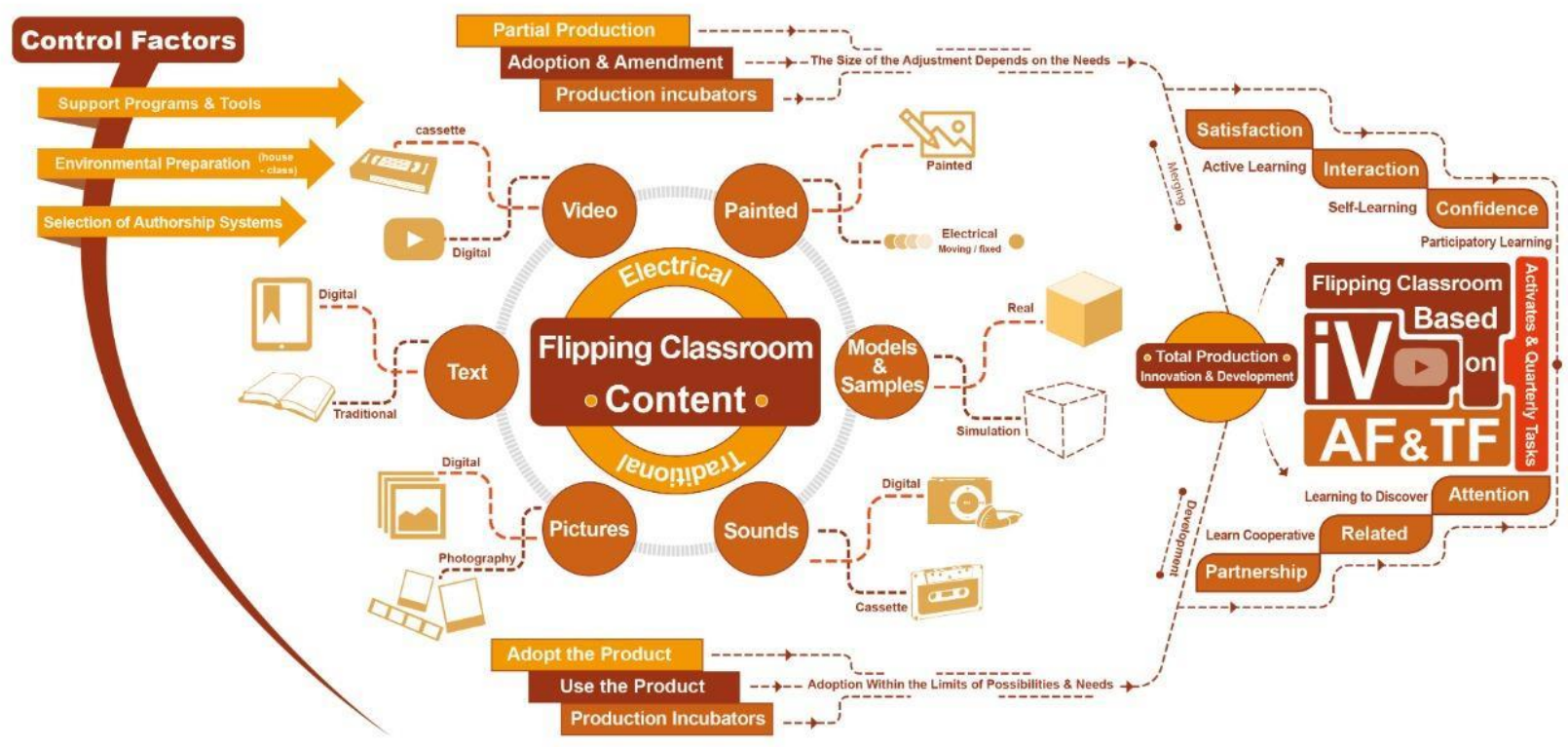

Figure 5: The development stage and the production of the necessary learning objects IV in the FC two types of feedback (AF and TF), characterized by the following: (Integration and partnership

After producing the videos and montaging and rendering operations, the videos were uploaded to YouTube. Playposit platform was used to convert the videos into IV, as the interactions were added to each video according to the specific scenario. Finally, we got the IV. Wix was used to build an eenvironment to display IVs and manage the learning environment, by using one of the ready-made templates and modifying them to suit learning topics and the needs of outstanding learners. All of that was linked to IV, by defining learning paths for each sample of the four research samples, allowing learner access to the path of his learning only.

At the end of the stage, a back-learning environment based on the IV was produced with between the components of the content, confidence in the content, multiple interactions between all the elements, product satisfaction, intrigue, diversity, and versatility), while emphasizing the presence of diversity in the learning method (commensurate with the content and place of learning) such as problem-based learning, participatory learning, and self-learning within the IV-FC. It presented during $\mathrm{AF}$ or $\mathrm{TF}$, and uploaded to the below link:

https://intervideoedit.wixsite.com/plantreproduction

Fourth, the experiment and evaluation stage: This occurred in two main processes (figure 6):

Formative evaluation: The production stages of the FC were evaluated across all stages of the FC 
educational design, providing interim feedback, and the subsequent progressive adjustments to ensure the quality of the outputs of each stage.
The final evaluation: It included the learners' evaluation where a pilot study was conducted on 20 students dealing with an IV-FC environment, assessing the comfort and ease of use and ability to suffice before publication and application.

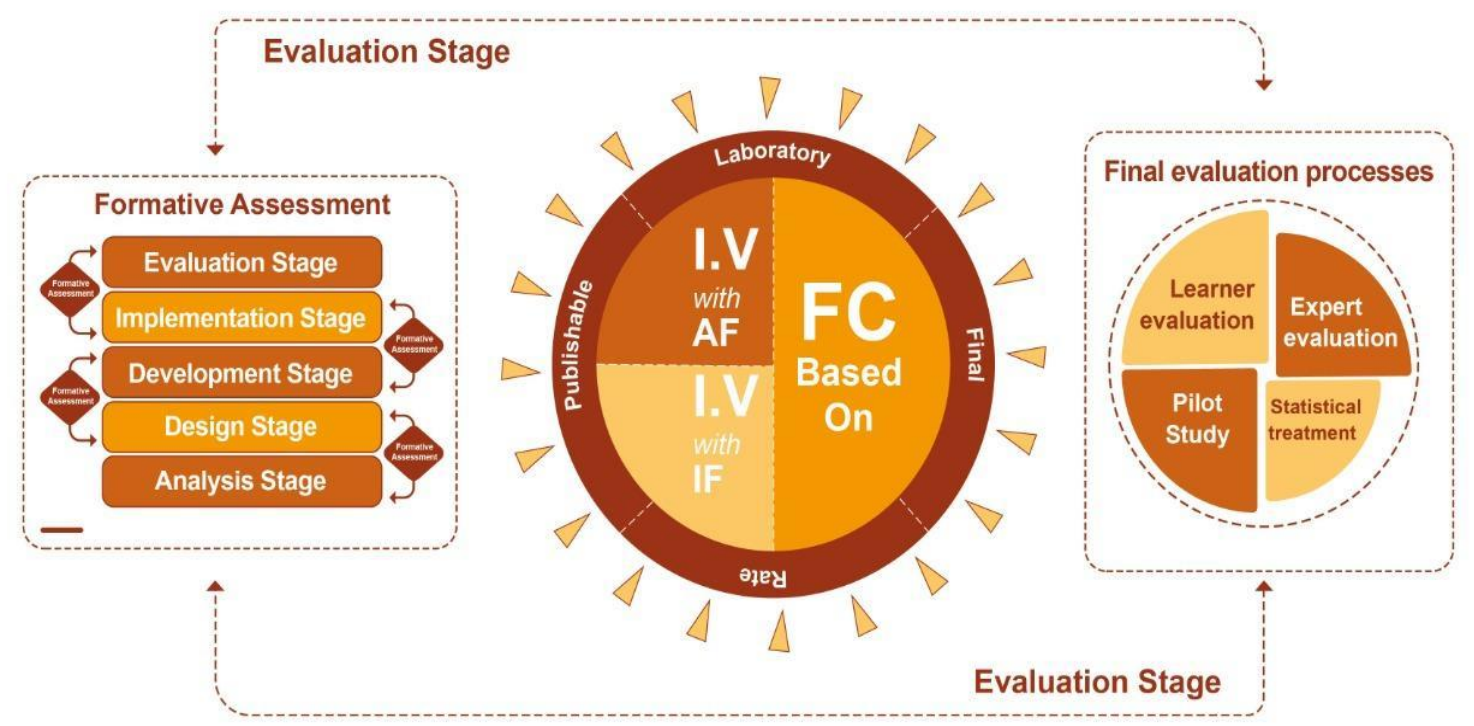

Figure 6: Stage of evaluation and experimental implementation

Expert evaluation: Specialists assessed the learning environment per the adopted technical and educational standards to ensure its sincerity and sufficiency. The average percentage of agreement on the quality of dual-feedback IV-FC environment was 93.6\%: a high ratio. Recommendations were setting an icon skipping the introduction, correcting some language errors, and modifying some video clips in terms of size and timing. Afterwards, the FCs were finalized.

Fifth: The Implementation Stage

The interaction with the IV-FC began by applying the LS scale (students were divided into four experimental groups), followed by providing the student with credentials for the learning interface with its two types: AF \&TF.

The learning method was explained by IVFC for the learners with a guide when needed, declaring the terms of achievement. The research team supervised ethical commitment, technical support, and management of the FC throughout the process. 


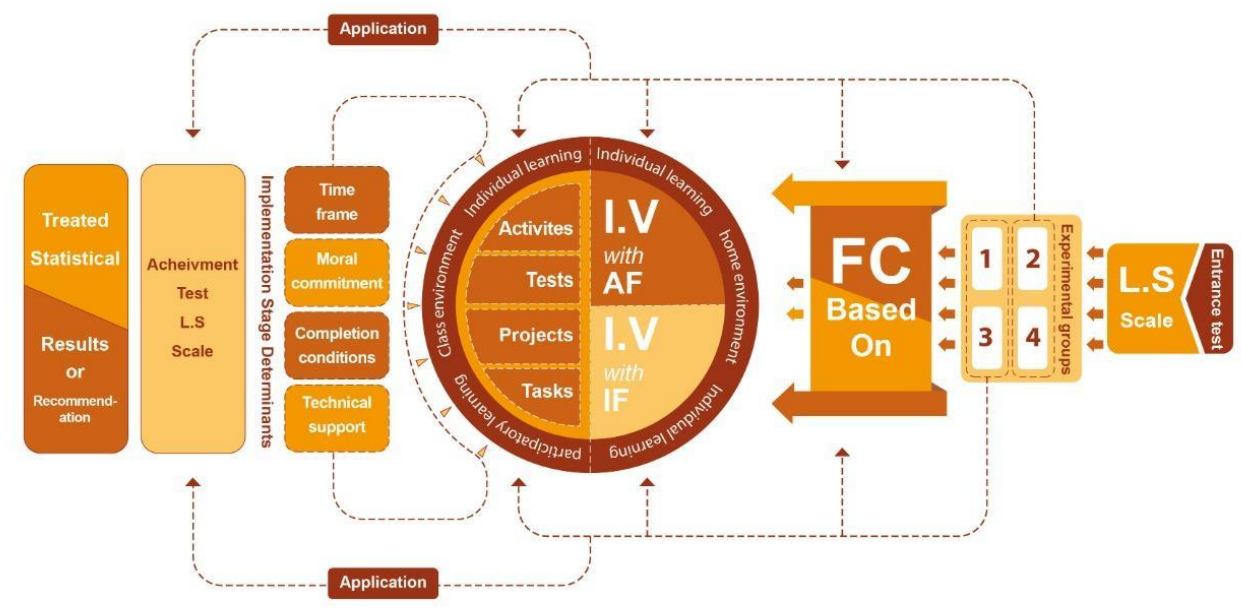

Figure 7: The operations of the implementation confirmation stage

The evaluation stage used measures of PKMS, educational activities, and tasks delivered to students. Maintaining the timeframe for learning per the flexibility guaranteed by the determinants of education in the FC, the experimental treatment was applied within 2-20 November 2019 in cooperation with the Hail Gifted Center.

- Sixth: Quality Assurance Stage
This stage had multiple dimensions: technical, economic, social, and educational dimensions. It also included the first follow-up process (figure 8) including three main metrics: technical support (solving programming problems faced at home), technical educational/academic support (provided to learners f2f), and continuous review (periodic reviews to improve performance and maximize strengths to ensure the quality of learning).

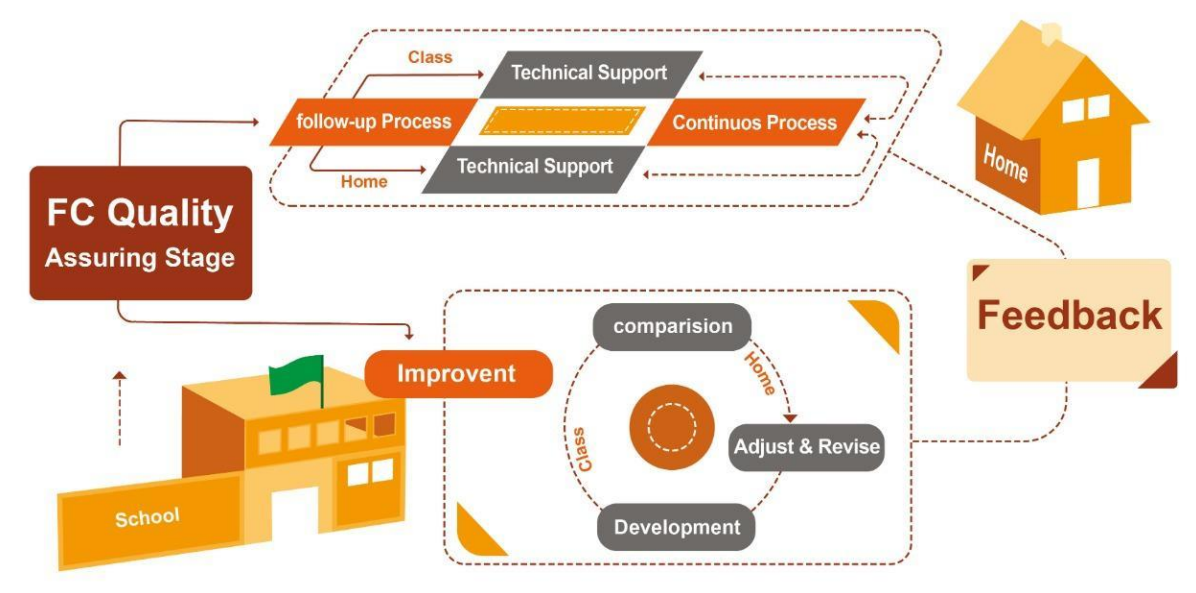

Figure 8: Quality Assurance Stage

Second: The improvement process: It included three main procedures: comparison with similar educational products to identifying them and the extent of their implementation of educational requirements, control and revision (a comprehensive review of the scientific content and production programs), and the continuous development of the FC whether partial or radical.

\section{Findings}

\section{Limitations}

First, the participants were few from different schools (due to the small population of gifted and talented students), limiting the 
generalization of this study. Second, this study tried to study interaction with only some learning styles and feedback type on IV-FC, achievement, and PKMS. Third, the research was limited to a single science topic: plant reproduction. Fourth, the research omitted talented students with convergent and divergent LSs due to a lack of them in the Gifted Center in Hail. The effects of gender, IQ, digital skills, and previous experiences, especially in [4], findings, stress the importance of these variables Implications
A one-size-fits-all educational model does not work for today's talented classroom. We should create an interactive e-learning environment to encourage different talented students and their learning styles to express and exchange their thoughts and ideas and collaboratively solve problems.

\section{Results}

- To answer Q1, an independent sample t-test was used to test the difference between the TF and $\mathrm{AF}$ in the IV-FC on the PKMS for STS, as the following in table (2):

- Table 2: Results of the difference between the TF/AF in the IV-FC on PKMS for STS

\begin{tabular}{|c|c|c|c|c|c|c|c|}
\hline PKMS & $\mathbf{L S}$ & $\mathbf{N}$ & Mean & Std. Deviation & $\mathbf{T}$ & df & Sig \\
\hline \multirow[t]{2}{*}{ Access } & TF & 25 & 43.44 & 2.70 & \multirow[t]{2}{*}{1.59} & \multirow[t]{2}{*}{48} & \multirow{2}{*}{$\begin{array}{c}0.120 \\
\text { Not Sig. }\end{array}$} \\
\hline & $\mathrm{AF}$ & 25 & 44.64 & 2.64 & & & \\
\hline \multirow[t]{2}{*}{ Evaluating } & TF & 25 & 37.48 & 3.73 & \multirow[t]{2}{*}{0.92} & \multirow[t]{2}{*}{48} & \multirow{2}{*}{$\begin{array}{c}0.362 \\
\text { Not sig. }\end{array}$} \\
\hline & $\mathrm{AF}$ & 25 & 39.20 & 8.55 & & & \\
\hline \multirow[t]{2}{*}{ Organizing } & TF & 25 & 41.48 & 4.06 & \multirow[t]{2}{*}{1.15} & \multirow[t]{2}{*}{48} & \multirow{2}{*}{$\begin{array}{c}0.255 \\
\text { Not Sig. }\end{array}$} \\
\hline & $\mathrm{AF}$ & 25 & 42.60 & 2.67 & & & \\
\hline \multirow[t]{2}{*}{ Analysis } & TF & 25 & 43.76 & 2.91 & \multirow[t]{2}{*}{1.68} & \multirow[t]{2}{*}{48} & \multirow{2}{*}{$\begin{array}{c}0.100 \\
\text { Not sig. }\end{array}$} \\
\hline & $\mathrm{AF}$ & 25 & 42.60 & 1.84 & & & \\
\hline \multirow[t]{2}{*}{ Conveying } & TF & 25 & 42.40 & 3.02 & \multirow[t]{2}{*}{0.74} & \multirow[t]{2}{*}{48} & \multirow{2}{*}{$\begin{array}{c}0.466 \\
\text { Not Sig. }\end{array}$} \\
\hline & $\mathrm{AF}$ & 25 & 43.00 & 2.73 & & & \\
\hline \multirow[t]{2}{*}{ Sharing } & TF & 25 & 38.48 & 4.11 & \multirow[t]{2}{*}{0.86} & \multirow[t]{2}{*}{48} & 0.393 \\
\hline & $\mathrm{AF}$ & 25 & 39.48 & 4.09 & & & Not sig \\
\hline \multirow[t]{2}{*}{ Providing } & TF & 25 & 41.20 & 3.10 & \multirow[t]{2}{*}{0.30} & \multirow[t]{2}{*}{48} & 0.763 \\
\hline & $\mathrm{AF}$ & 25 & 41.48 & 3.41 & & & Not sig. \\
\hline \multirow[t]{2}{*}{ Total } & TF & 25 & 288.24 & 10.21 & \multirow[t]{2}{*}{1.79} & \multirow[t]{2}{*}{48} & \multirow{2}{*}{$\begin{array}{c}0.079 \\
\text { Not sig }\end{array}$} \\
\hline & $\mathrm{AF}$ & 25 & 293.00 & 8.47 & & & \\
\hline
\end{tabular}

The results (table 2 and figure 9) revealed the lack of statistical differences between the TF and $\mathrm{AF}$, in terms of (Access to, Evaluating, Organizing, Analysis, Conveying, Share, and Providing) processing ideas and information skills of IV on the PKMS, as well as the absence of statistical differences between the TF and AF in the total score of the IV-FC on the PKMS.

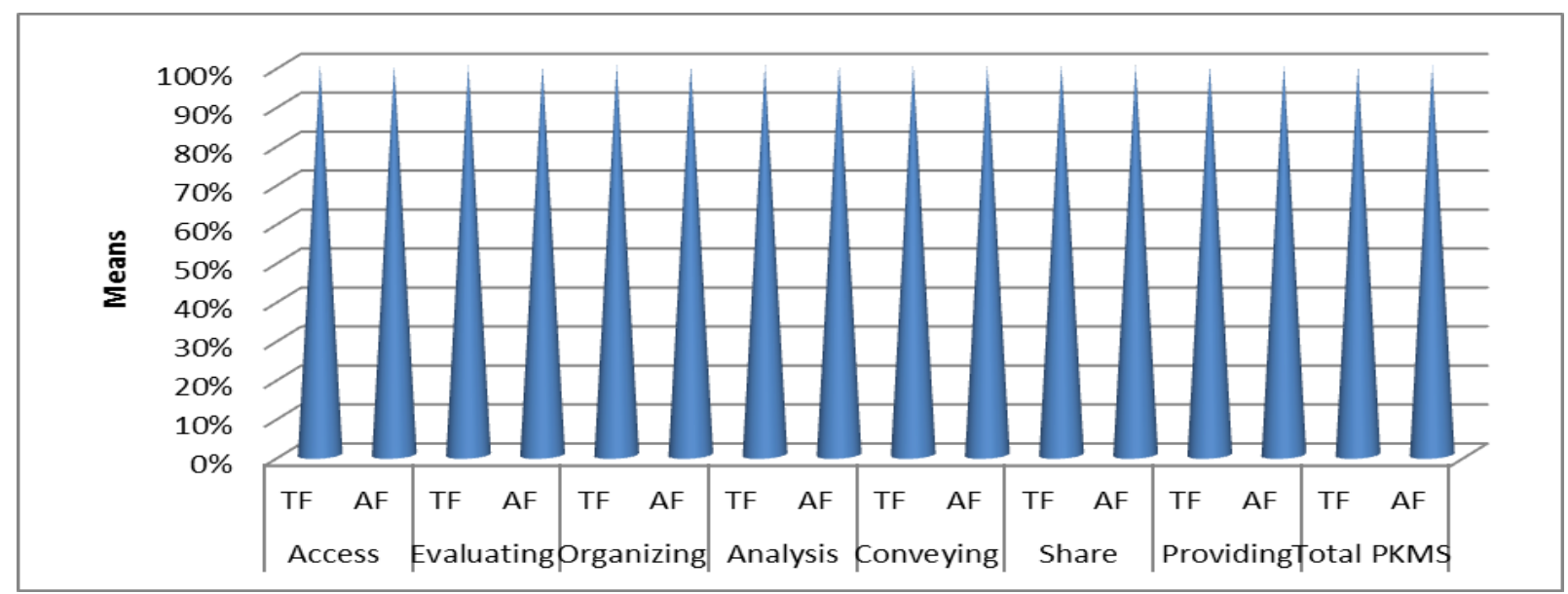

Figure 9: Difference between means of the PKMS Skills for the TF/AF in IV-FC 
- To answer Q2, an independent sample t-test was used to test the statistical difference between the TF/AF in the IV-FC on the achievement for STS as in table (3):

- Table 3: The results of the difference between TF/AF in IV-FC on STS

\begin{tabular}{|c|c|c|c|c|c|c|}
\hline Feedback in IV & N & Mean & Std. Deviation & T & df & Sig \\
\hline TF & 26 & 36.0769 & 1.95802 & 0.42 & 50 & 0.668 \\
AF & 26 & 35.4231 & 7.47354 & & & Not sig. \\
\hline
\end{tabular}

- The results (from Table $3 \&$ Fig 10) showed the lack of statistical differences between the TF and AF in IV on the achievement for STS. Although the average of TF is higher than AF

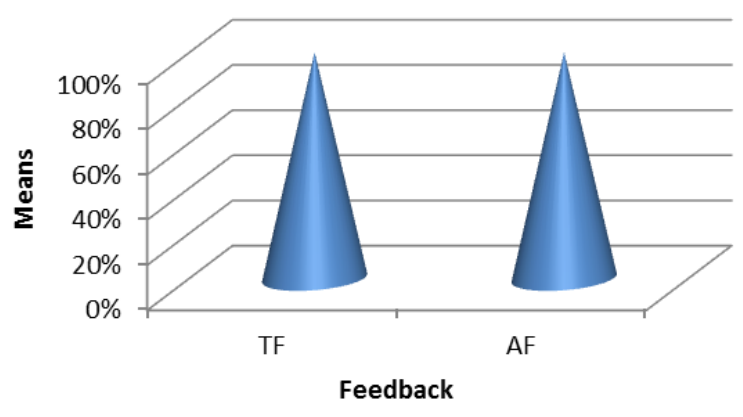

Figure 10: Difference between means of the achievement for the TF/AF in IV-FC
From the results for Q1\& Q2, although there is a clear improvement of PKMS and achievement induced by IV-FC, there are no evident differences between TF and AT.

- To answer Q3, independent samples t-test had been used to test the differences between the convergent and distant learning styles in IV-FC on PKMS for STS as in table (4):

\begin{tabular}{|c|c|c|c|c|c|c|c|}
\hline PKMS & LS & $\mathbf{N}$ & Mean & $\begin{array}{c}\text { Std. } \\
\text { Deviation }\end{array}$ & $\mathbf{t}$ & Df & Sig \\
\hline \multirow{2}{*}{ Access } & Divergence & 24 & 42.87 & 3.12 & \multirow[t]{2}{*}{3.17} & \multirow[t]{2}{*}{48} & \multirow{2}{*}{$\begin{array}{c}0.003 \\
\text { Sig. }\end{array}$} \\
\hline & Convergence & 26 & 45.11 & 1.72 & & & \\
\hline \multirow[t]{2}{*}{ Evaluating } & Divergence & 24 & 37.71 & 8.40 & \multirow[t]{2}{*}{0.65} & \multirow[t]{2}{*}{48} & 0.521 \\
\hline & Convergence & 26 & 38.92 & 4.40 & & & Not sig. \\
\hline \multirow[t]{2}{*}{ Organizing } & Divergence & 24 & 40.45 & 3.83 & \multirow[t]{2}{*}{3.44} & \multirow[t]{2}{*}{48} & 0.001 \\
\hline & Convergence & 26 & 43.50 & 2.28 & & & Sig. \\
\hline \multirow[t]{2}{*}{ Analysis } & Divergence & 24 & 43.71 & 2.29 & \multirow[t]{2}{*}{1.46} & \multirow[t]{2}{*}{48} & 0.151 \\
\hline & Convergence & 26 & 42.69 & 2.60 & & & Not sig. \\
\hline \multirow[t]{2}{*}{ Conveying } & Divergence & 24 & 43.75 & 2.64 & \multirow[t]{2}{*}{2.63} & \multirow[t]{2}{*}{48} & 0.011 \\
\hline & Convergence & 26 & 41.73 & 2.77 & & & Sig. \\
\hline \multirow[t]{2}{*}{ Sharing } & Divergence & 24 & 39.08 & 3.39 & \multirow[t]{2}{*}{0.17} & \multirow[t]{2}{*}{48} & 0.866 \\
\hline & Convergence & 26 & 38.88 & 4.71 & & & Not sig \\
\hline \multirow[t]{2}{*}{ Providing } & Divergence & 24 & 40.62 & 2.61 & \multirow[t]{2}{*}{1.52} & \multirow[t]{2}{*}{48} & 0.135 \\
\hline & Convergence & 26 & 42 & 3.64 & & & Not sig. \\
\hline \multirow[t]{2}{*}{ Total PKMS } & Divergence & 24 & 288.20 & 10.80 & \multirow[t]{2}{*}{1.74} & \multirow[t]{2}{*}{48} & 0.088 \\
\hline & Convergence & 26 & 292.84 & 7.88 & & & Not sig \\
\hline
\end{tabular}

- There were statistical differences between the learning styles in the access and organizing aspects of ideas and information skills of IVFC on PKMS for STS for the convergence 


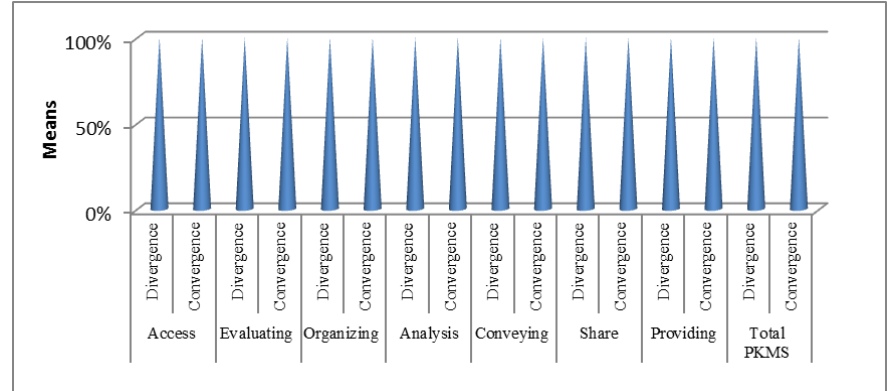

Figure 11: Difference between means of the PKMS

\section{efficiencies for the learning styles}

Statistics remained marginally similar in the rest of PKMS across the learning styles. Also, this remained the same when using IV-FC.

- To answer Q4, an independent sample t-test was used to test the statistical differences between LS in IV-FC on achievement of STS, as in table 5 and figure 12 :

Table 5: Results of difference between the LS (convergent- distant) in IV-FC on achievement of STS

\begin{tabular}{|c|c|c|c|c|c|c|}
\hline LS & N & Mean & $\begin{array}{c}\text { Std. } \\
\text { Deviation }\end{array}$ & T & Df & Sig \\
\hline Divergence & 26 & 34.42 & 7.27 & -1.80 & 50 & $\begin{array}{c}0.007 \\
\text { sig }\end{array}$ \\
\hline Convergence & 26 & 37.08 & 1.83 & -83
\end{tabular}

There were statistical differences between learning styles in IV-FC on students' achievement in favor of convergence; the average of convergence exceeded that of divergence's

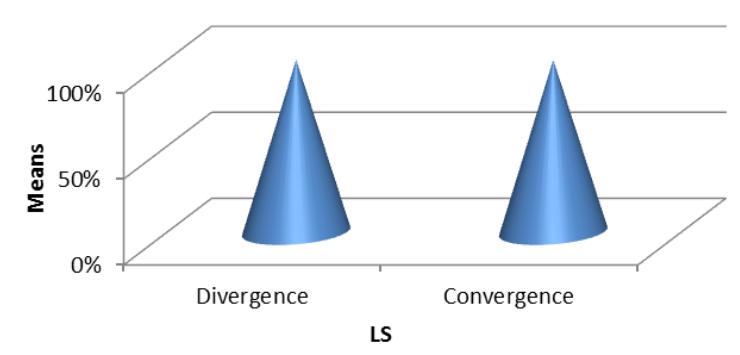

Figure 12: Difference between means of achievement for learning styles
- To answer Q5, a two-way ANOVA was used to test the TF-AF interaction in the IV and learning styles and its effect on PKMS. Each of the seventh PKMS was treated separately with varying degrees:

For access to ideas and information skills, the data were analyzed as shown in table 6: there was no statistical TF-AF interaction in IV-FC and the learning style influencing the access to ideas and information skill.

Table 6: Interaction between TF-AF in IV-FC \& learning styles among students' access to ideas and information skill

\begin{tabular}{|c|c|c|c|c|c|}
\hline Source & Type III Sum of Squares & df & Mean Square & F & Sig. \\
\hline Corrected Model & 93.36 & 3 & 31.12 & 5.33 & .003 \\
\hline method * LS & 12.72 & 1 & 12.72 & 2.17 & .147 \\
\hline Error & 268.55 & 46 & 5.83 & & \\
\hline Total & 97338 & 50 & & & \\
\hline Corrected Total & 361.92 & 49 & & & \\
\hline
\end{tabular}

statistical interaction between TF-AF in IV-FC and

For evaluating ideas and information skill, LS influencing evaluating ideas and information the data were analyzed as in table 7: there was no skill.

Table 7: Interaction between TF and AF in IV-FC and learning styles evaluating ideas and information skill

\begin{tabular}{|c|c|c|c|c|c|}
\hline Source & Type III Sum of Squares & df & Mean Square & F & Sig. \\
\hline Corrected Model & 111.07 & 3 & 37.02 & .84 & .477 \\
\hline Intercept & 73287.21 & 1 & 73287.21 & 1670.44 & .000 \\
\hline method * LS & 55.67 & 1 & 55.67 & 1.26 & .266 \\
\hline Error & 2018.14 & 46 & 43.87 & & \\
\hline Total & 75627 & 50 & & & \\
\hline Corrected Total & 2129.22 & 49 & & & \\
\hline
\end{tabular}

For organizing ideas and information skill, table 8 shows data analysis: there were statistical 
interactions between $\mathrm{TF}-\mathrm{AF}$ in the $\mathrm{IV}-\mathrm{FC}$ and information skill. learning styles influencing the organizing ideas and

Table 8: Interaction between TF and AF in IV-FC's and LS on STS organizing ideas and information skill

\begin{tabular}{|c|c|c|c|c|c|}
\hline Source & Type III Sum of Squares & Df & Mean Square & F & Sig. \\
\hline Corrected Model & 312.38 & 3 & 104.12 & 17.64 & .000 \\
\hline Intercept & 87971.54 & 1 & 87971.54 & 14903.18 & .000 \\
\hline Feedback * LS & 181.24 & 1 & 181.24 & 30.70 & .000 \\
\hline Error & 271.53 & 46 & 5.90 & & \\
\hline Total & 88952 & 50 & & & \\
\hline Corrected Total & 583.92 & 49 & & & \\
\hline
\end{tabular}

To determine the mean differences between the using the Tukey test as following (table 9 \&figure four groups, we performed the post hoc analysis 12):

Table 9: Tukey test results for the TF-AF interaction in IV-FC and LS on students' organizing ideas and information skill

\begin{tabular}{|c|c|c|c|c|}
\hline Skill & Feedback in IV & LS & Mean & Std. Error \\
\hline \multirow{3}{*}{ Organizing } & \multirow{2}{*}{ Text } & Divergence & 37.917 & .701 \\
\cline { 2 - 5 } & \multirow{2}{*}{ Audio } & Convergence & 44.769 & .674 \\
\cline { 2 - 5 } & & Divergence & 43.000 & .701 \\
\cline { 2 - 5 } & & Convergence & 42.231 & .674 \\
\hline
\end{tabular}

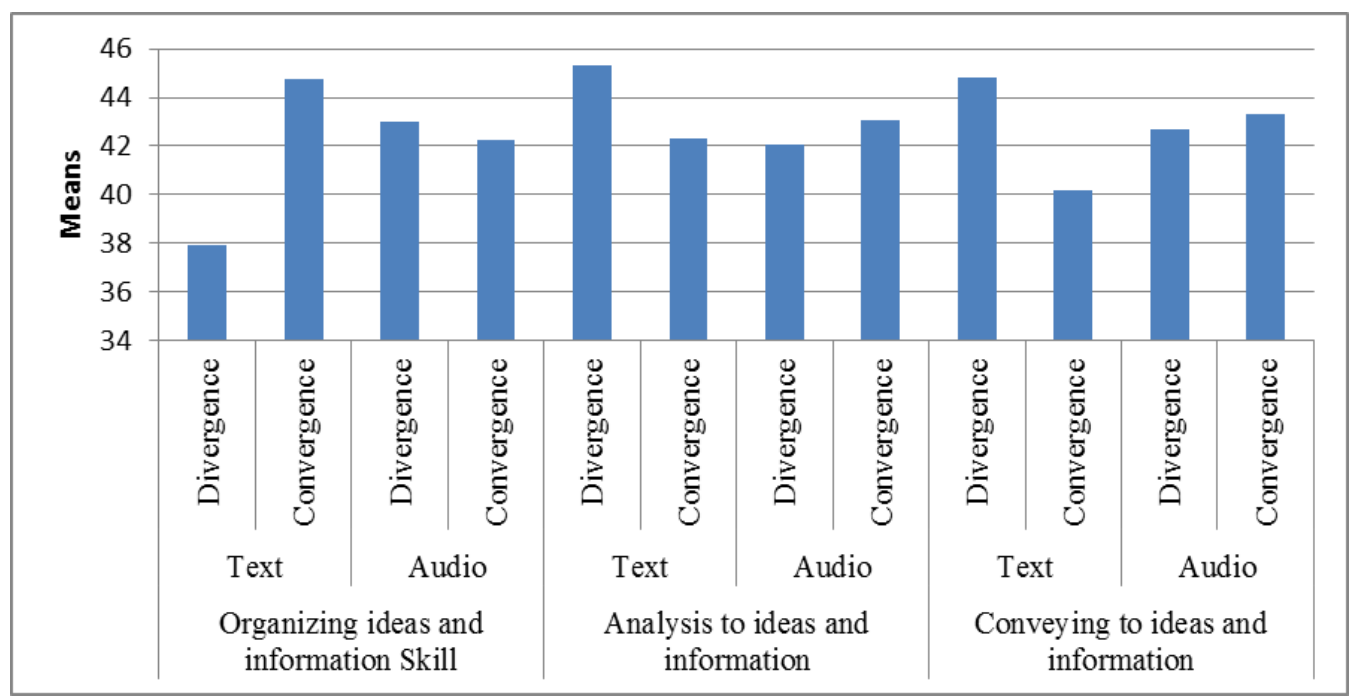

Figure 12: interactions' results between TF-AF in IV-FC and learning styles on students' organizing, analysis, convergence of ideas and information skills

interaction effects between the TF and AF in IV-FC

For analysis of ideas and information skill, and LS influencing analysis of ideas and the data analysis is in table 10; there were statistical information skill.

Table 10: interaction results between TF-AF in IV-FC and learning styles on students' analysis of ideas and information skill

\begin{tabular}{|c|c|c|c|c|c|}
\hline Source & Type III Sum of Squares & Df & Mean Square & F & Sig. \\
\hline Corrected Model & 80.10 & 3 & 26.70 & 5.50 & .003 \\
\hline Intercept & 93164.08 & 1 & 93164.08 & 19193.97 & .000 \\
\hline method * LS & 50.40 & 1 & 50.40 & 10.38 & .002 \\
\hline Error & 223.27 & 46 & 4.85 & & \\
\hline Total & 93529 & 50 & & & \\
\hline Corrected Total & 303.38 & 49 & & & \\
\hline
\end{tabular}


To determine the mean differences between the four groups we performed the post hoc analysis using the Tukey test, as in (Fig $12 \&$ table 11).

LS (convergent and divergent) among STS on Analysis ideas \& information skill

\begin{tabular}{|c|c|c|c|c|}
\hline \multicolumn{1}{|c|}{ LS (convergent and divergent) among STS on Analysis ideas \& information skill } \\
\hline \multirow{3}{*}{$\begin{array}{c}\text { Analysis of ideas } \\
\text { and information }\end{array}$} & Method & LS & Mean & Std. Error \\
\cline { 2 - 5 } & \multirow{2}{*}{$\mathrm{TF}$} & Divergence & 45.33 & .636 \\
\cline { 2 - 5 } & & Convergence & 42.30 & .611 \\
\cline { 2 - 5 } & Divergence & 42.08 & .636 \\
\cline { 2 - 5 } & Convergence & 43.07 & .611 \\
\hline
\end{tabular}

For conveying ideas and information skill, learning styles affecting the analysis of ideas and table 12 shows data analysis; there were statistical information skill. interaction between $\mathrm{TF}$ and $\mathrm{AF}$ in $\mathrm{IV}-\mathrm{FC}$ and

Table 12: Interaction between TF-AF in IV-FC and learning styles on students' conveying ideas and information skill

\begin{tabular}{|c|c|c|c|c|c|}
\hline Source & Type III Sum of Squares & Df & Mean Square & F & Sig. \\
\hline Corrected Model & 143.70 & 3 & 47.90 & 8.44 & .000 \\
\hline Intercept & 91190.88 & 1 & 91190.88 & 16084.59 & .000 \\
\hline method $*$ LS $_{\text {Error }}^{88.32}$ & 1 & 88.32 & 15.57 & .000 \\
\hline Total & 260.79 & 46 & 5.66 & & \\
\hline Corrected Total & 91569 & 50 & & & \\
\hline
\end{tabular}

To determine the mean differences between

the four groups, we performed the post hoc analysis

using the Tukey test (as in table 13):

Table 13: Tukey test results for the TF and AF in IV-FC and

Learning styles on students' conveying ideas and information skill

\begin{tabular}{|c|c|c|c|c|}
\hline Skill & Method & LS & Mean & Std. Error \\
\hline Conveying & \multirow{2}{*}{$\begin{array}{c}\text { Text } \\
\text { Infeas and }\end{array}$} & Divergence & 44.83 & .687 \\
\cline { 2 - 4 } Information & & Convergence & 40.15 & .660 \\
\cline { 2 - 4 } & \multirow{2}{*}{ Audio } & Divergence & 42.66 & .687 \\
\cline { 3 - 5 } & & Convergence & 43.30 & .660 \\
\hline
\end{tabular}

For sharing ideas and information skill, IV-FC and LS influencing sharing ideas and table 14 shows data analysis; there were no information skill statistical interaction effects between $\mathrm{TF}$ and $\mathrm{AF}$ in

Table 14: Interaction between TF-AF in IV-FC and learning styles on students' sharing ideas and information skill

\begin{tabular}{|c|c|c|c|c|c|}
\hline Source & Type III Sum of Squares & Df & Mean Square & F & Sig. \\
\hline Corrected Model & 15.87 & 3 & 5.29 & .302 & .823 \\
\hline Intercept & 75865.93 & 1 & 75865.93 & 4334.64 & .000 \\
\hline Method * style & 2.88 & 1 & 2.88 & .16 & .687 \\
\hline Error & 805.10 & 46 & 17.50 & & \\
\hline Total & 76793 & 50 & & & \\
\hline Corrected Total & 820.98 & 49 & & & \\
\hline
\end{tabular}

For providing ideas and information skill, IV-FC and learning styles providing ideas and table 15 shows data analysis; there were no information skill. statistical interaction effects between $\mathrm{TF}$ and $\mathrm{AF}$ in

Table 15: interaction between TF-AF in IV-FC and learning styles on students' providing ideas and information skill

\begin{tabular}{|c|c|c|c|c|c|}
\hline Source & Type III Sum of Squares & Df & Mean Square & F & Sig. \\
\hline Corrected Model & 30.17 & 3 & 10.05 & .95 & .421 \\
\hline Intercept & 85199.59 & 1 & 85199.59 & 8113.49 & .000 \\
\hline Method * style & 5.60 & 1 & 5.60 & .53 & .469 \\
\hline Error & 483.04 & 46 & 10.50 & & \\
\hline Total & 85963 & 50 & & & \\
\hline Corrected Total & 513.22 & 49 & & & \\
\hline
\end{tabular}


For total PKMS, table 16 shows data analysis; TF and AF in IV-FC and learning styles influencing there were no statistical interaction effects between the total PKMS

Table 16: interaction between TF-AF in IV-FC and learning styles on students' providing ideas and information skill

\begin{tabular}{|c|c|c|c|c|c|}
\hline Source & Type III Sum of Squares & Df & Mean Square & F & Sig. \\
\hline Corrected Model & 567.09 & 3 & 189.03 & 2.20 & .100 \\
\hline Intercept & 4213551.47 & 1 & 4213551.47 & 49160.23 & .000 \\
\hline Method * style & 15.43 & 1 & 15.43 & .18 & .673 \\
\hline Error & 3942.68 & 46 & 85.71 & & \\
\hline Total & 4227509 & 50 & & & \\
\hline Corrected Total & 4509.78 & 49 & & & \\
\hline
\end{tabular}

- To answer Q6, a two-way ANOVA was used to test the interaction as in table 16 :

Table 16: Interaction between TF-AF in IV-FC and learning styles on students' achievement

\begin{tabular}{|c|c|c|c|c|c|}
\hline Source & Type III Sum of Squares & df & Mean Square & F & Sig. \\
\hline Corrected Model & 143.28 & 3 & 47.76 & 1.69 & .181 \\
\hline Intercept & 66459.25 & 1 & 66459.25 & 2355.212 & .000 \\
\hline Feedback & 5.56 & 1 & 5.56 & .197 & .659 \\
\hline LS & 91.55 & 1 & 91.56 & 3.25 & .007 \\
\hline Feedback* LS & 46.17 & 1 & 46.17 & 1.64 & .207 \\
\hline Error & 1354.46 & 48 & 28.22 & & \\
\hline Total & 67957 & 52 & & & \\
\hline Corrected Total & 1497.750 & 51 & & & \\
\hline
\end{tabular}

There was no interaction between $\mathrm{TF}$ and $\mathrm{AF}$ in IV-FC and the learning style on students' achievement.

\section{Discussion}

The results revealed that in $\mathrm{IV}-\mathrm{FC}$, there were no statistical differences between $\mathrm{TF}$ and $\mathrm{AF}$ concerning achievement or skills, though TF's averages exceeded those of AF. However, there was a clear improvement in skills and achievement. Also, there were no statistical differences between learning styles (convergent- distant) on students' skills and achievement in flipped classes. There were no statistical interaction effects between TF and $\mathrm{AF}$ in IV-FC and LS influencing skills and achievement, though there are some interaction effects in some skills (conveying, analysis, and organizing).

We attribute this to the retention-supportive role of interactive videos. Previous studies agree that IV guides the learner's attention and motivation increases achievement, knowledge, and formative assessment [42]; [48]; [65]; [86]. Also, the findings agree with [11]; [19]; [36]; [79]; [80]; [87]. That IV would improve problem-solving, communication, and reasoning. And it was seen that FC facilitates motivation, autonomy, and commitment [14]; [42]. However, FC and IV are irrelevant to achievement, skills, and performance [62]. Same for which confirmed that the LS affects different levels of performance and achievement [88]. Interactive elements are designed to allow the user to reflect on the information delivered before moving to the next step in the learning process [89]. So, interactive components ensured that the learner comprehended the content instead of simply viewing it. Also, research showed that interactive videos are a powerful tool in education encouraging reflection and student-directed learning [90]; [91]. Hence, science-talented students are encouraged by the use of these IV-FC where most of them maintained high performance. The environment they operated within seems irrelevant to their will to consistently achieve and complete assignments regardless of the challenge [3]; [6].

Interpretation in the Light of Learning Theories

This concept of FC is a combination of behaviorist principles and constructivist ideology. Unlike constructivism, behaviorism focuses places the teacher as the center of instruction and content includes tutorials, lectures, demonstrations, and other teacher-focused instruction. The classroom was conducted as so.

Alternatively, constructivism is based on the principle that an individual uses prior knowledge and experience to build and understand new concepts; individuals possess the information and they try to unravel this information [23]. 
Accordingly, knowledge was constructed or reconstructed by students when they utilized interactive videos. This construction and reconstruction were done via active learning strategies such as problem-based learning. Through interactive videos, knowledge construction occurred. Students are comprehending content at a higher level rather than memorizing it, as the latter contributes to the problem.

Sociocultural conflict theory is also relevant to the FC-learning approach, suggesting that discrepancy or conflict sparks cognitive development. Socio-cognitive conflict theory identifies conflict as an essential ingredient to induce cognitive change [18], which occurred during the use of the problem-solving method in F2F learning or during the implementation of assignments and activities in IV.

\section{Conclusion and Suggestions}

In general, IV-FC, according to results, showed no $\mathrm{TF}-\mathrm{AF}$ statistical differences in the achievement or skills of students. Also. there were no statistical differences between learning styles (convergent and distant) on student's skills or achievement, same for $\mathrm{TF}-\mathrm{AF}$ interaction and learning style. Though some interaction effects were noticed in some PKMS (conveying, analyzing, and organizing.

IV-based FC provides deep learning for STS; IV raises the learner's motivation and attracts his attention, putting STS in continuous interaction with the program with the possibility of providing feedback. Availing gifted learners with appropriate choices for the accelerated course in their area of talent in this type of blended-learning model can help them fulfill their potential for achievement and PKMS.

Contributors reported that the majority of their students described knowledge of their LS as a helpful tool. It improved perceptions of their abilities and empowered them to strive beyond what they had previously accomplished. When students understand how they learn best, they inevitably adjust conditions and devise strategies for facilitating their progress [92]. The integration between the IV and the materials presented during it ideally provided the educational tasks that provide information and skills through real-life situations, same for learner's control, feedback type, and the frequency of the training affecting the mastery of educational tasks. Also, the value of feedback and its importance enhanced students' learning and raised awareness of the strengths and weaknesses of their learning, and that the quality of the feedback provided through IV had an immediate impact on PKMS.

Future research could address the diminishing motivation occurring with the IV-based FC setting. Specifically, how to design IV-based FC with kinds of feedback that could encourage students to develop KPMS and deepen their understanding of topics. This study can be replicated with a large sample size besides including female students and other learning styles. However, the strength of this study lies in its examination of the interaction with learning styles and feedback type on IV-FC and achievement and PKMS, allowing us to explore the interaction effects. Future studies need to unravel the differential effects of matched and mismatched learning styles and kind of feedback in IV to project educational success and gained skills. We must put more effort into researching what kind of e-environments will stimulate talented students' interests and learning needs. Also, further research can be conducted about supporting the flipped classroom method with different gamification practices and teaching approaches or what kind of technology is more suitable for improving talented PKMS.

\section{Acknowledgments:}

The authors acknowledge the support provided by Deanship of Scientific Research at the UOH, Hail, KSA.

Funding: The search (No. 0160976) funded by Scientific Research at the UOH, Hail, KSA. The funding source had no involvement in any aspect of the study design, delivery or publication

\section{REFERENCES}

[1] Reis, S. (2007). No child left bored. School Administrator, 64(2), 22-26.

[2] Swan, B., Coulombe-Quach, X. L., Huang, A., Godek, J., Becker, D., \& Zhou, Y. (2015). Meeting the needs of gifted and talented students: Case study of a virtual learning lab in a rural middle school. Journal of Advanced Academics, 26(4), 294-319.

[3] Rayneri, L. J., Gerber, B. L., \& Wiley, L. P. (2006). The relationship between classroom environment and the learning style preferences of gifted middle school students and the impact on levels of performance. Gifted child quarterly, 50(2), 104-118. 
[4] Stewart, E. D. (1981). Learning styles among gifted/talented students: Instructional technique preferences. Exceptional Children, 48(2), 134-138.

[5] Aliakbari, M., \& Qasemi, N. (2012). On the relationship between Iranian EFL learners' learning style preference and their gender, proficiency level and achievement score. International Journal of Pedagogies and Learning, 7(3), 275-283.

[6] Yoon, J., Kim, K. J., \& Koo, K. (2020). Enrichment program for the ethnic minority of gifted and talented students in science and engineering. International Journal of Science Education, Part B, 10 (1), 36-50.

[7] Housand, B. C., \& Housand, A. M. (2012). The role of technology in gifted students' motivation. Psychology in the Schools, 49(7), 706-715.

[8] Ibrahem, U. M., \& Alamro, A. R. (2021). Effects of Infographics on Developing Computer Knowledge, Skills and Achievement Motivation among Hail University Students. International Journal of Instruction, 14(1).

[9] Tse, W. S., Choi, L. Y., \& Tang, W. S. (2019). Effects of video- based flipped class instruction on subject reading motivation. British Journal of Educational Technology, 50(1), 385-398.

[10] Afzal, S., \& Masroor, I. (2019). Flipped Classroom Model for Teaching Undergraduate Students in Radiology. Journal of the College of Physicians and Surgeons Pakistan, 29(11), 1083-1086.

[11] Røe, Y., Rowe, M., Ødegaard, N. B., Sylliaas, H., \& Dahl-Michelsen, T. (2019). Learning with technology in physiotherapy education: design, implementation and evaluation of a flipped classroom teaching approach. BMC medical education, 19(1), 291.

[12] Ibrahem, U. M., Alamr, A. R. (2020). The Effect of Using Cinemagraph Pictures in Social Platforms and Mobile Applications in the Development of Peace Concepts among University of Hail Students, JOURNAL OF INFORMATION SCIENCE AND ENGINEERING, 37(6), (November 2021).

[13] Ho, J. (2015). 'Everyone flips, but should we?'-flipped classroom in the Hong Kong EFL context. Netter, 18. Retrieved 26 June 2016, from http://plate.fed.cuhk.edu.hk/netter/2015/07/29/issue18everyone-flips-but-should-we-flipped-classroom-in-thehong-kong-efl-context/

[14] Bicen, H., \& Taspolat, A. (2019). Students' Views on the Teaching Process Based on Social Media Supported Flipped Classroom Approach. BRAIN. Broad Research in Artificial Intelligence and Neuroscience, 10(4), 115-144.

[15] Lavelle, E., Vuk, J., \& Barber, C. (2013). Twelve tips for getting started using mixed methods in medical education research. Medical Teacher, 35(4), 272-276. https://doi.org/10.3109/0142159X.2013.759645

[16] Blair, E., Maharaj, C., \& Primus, S. (2016). Performance and perception in the flipped classroom. Education and information Technologies, 21(6), 1465-1482.

[17]Hanson, J. (2016). Surveying the experiences and perceptions of undergraduate nursing students of a flipped classroom approach to increase understanding of drug science and its application to clinical practice. Nurse education in practice, 16(1), 79-85.

[18] Fox-Turnbull, W. H., Docherty, P., \& Zaka, P. (2018). Learning engineering through the Flipped Classroom Approach-students' perspectives.

[19] Pattanaphanchai, J. (2019). An Investigation of Students' Learning Achievement and Perception using Flipped Classroom in an Introductory Programming Course: A Case Study of Thailand Higher Education. Journal of University Teaching and Learning Practice, 16(5), 4.

[20] Milman, N. B. (2012). The flipped classroom strategy: What is it and how can it best be used?. Distance learning, 9(3), 85-87.

[21] Galster, M., Mitrovic, A., \& Gordon, M. (2018, May). Toward enhancing the training of software engineering students and professionals using active video watching. In Proceedings of the 40th international conference on software engineering: Software engineering education and training (5-8). Gothenburg: IEEE.

[22] Ibrahim G. (2009). The effect of a program using interactive multimedia on motivation, cognitive achievement, and the level of motor skill performance for beginners in boxing, Master Thesis, Helwan University, Cairo.

[23] Sultan, A. S. (2018). The Flipped Classroom: An active teaching and learning strategy for making the sessions more interactive and challenging. Journal of Pakistan Medical Association, 68(4), 630.

[24] Siegle, D. (2014). Technology: Differentiating instruction by flipping the classroom. Gifted Child Today, 37(1), 5155.

[25] Trifonov, R., Nakov, O., Manolov, S., Tsochev, G., \& Pavlova, G. (2020). Possibilities for Improving the Quality of Cyber Security Education through Application of Artificial Intelligence Methods. In 2020 International Conference Automatics and Informatics (ICAI), (1-4). IEEE.

[26] Agnihotri, R., \& Troutt, M. D. (2009). The effective use of technology in personal knowledge management: A framework of skills, tools and user context. Online Information Review, 33(2), 329-342

[27] Caldwell, F. (2002). "Personal knowledge networks emerge with grassroots KM", Gartner Research Strategic Planning Research Note, 25 November.

[28] Cheong, R. K., \& Tsui, E. (2011). From skills and competencies to outcome- based collaborative work: Tracking a decade's development of personal knowledge management (PKM) models. Knowledge and Process Management, 18(3), 175-193

[29] Chatti, M. A. (2012). Knowledge management: A personal knowledge network perspective. Journal of Knowledge Management, 16(5), 829-844.

[30] Cheong KFR, Tsui E. (2011). Exploring linkage between personal knowledge management and organizational learning. In Personal Knowledge Management: Individual, Organization and Social Perspectives, Pauleen D, Gorman G (eds.). Gower: Surrey, England. 
[31]Higgison, S. (2004). YOUR SAY: PERSONALKNOWLEDGE MANAGEMENT. KNOWLEDGE MANAGEMENT-LONDON-, 7(7), 11-12.

[32] Agnihotri, R., \& Troutt, M. D. (2009). The effective use of technology in personal knowledge management: A framework of skills, tools and user context. Online Information Review, 33(2), 329-342.

[33] Tuta A. \& Lui, L. (2020). Serious Games Communication Aspects of VR Cadet Training Information Model, WSEAS Transactions on Business and Economics, Vol. 17, 560-569.

[34] Aljughaiman, A. M., \& Ayoub, A. E. (2013). Evaluating the effects of the oasis enrichment model on gifted education: A meta-analysis study. Talent Development \& Excellence, 5(1), 99-113

[35] Bishop, J. L., \& Verleger, M. A. (2013, June). The flipped classroom: A survey of the research. In ASEE national conference proceedings, Atlanta, GA (Vol. 30, No. 9, pp. 1-18).

[36] Comber, D. P., \& Brady-Van den Bos, M. (2018). Too much, too soon? A critical investigation into factors that make Flipped Classrooms effective. Higher Education Research \& Development, 37(4), 683-697.

[37] Bergmann, J., \& Sams, A. (2012). Flip your classroom: Reach every student in every class every day. International society for technology in education

[38] Hamdan, N., McKnight, P., McKnight, K., \& Arfstrom, K. M. (2013). The flipped learning model: A white paper based on the literature review titled a review of flipped learning. Flipped Learning Network/Pearson/George Mason University.

[39] Slebodnik, M., \& Riehl, C.F. (2009). Creating online tutorials at your libraries: Software choices and practical implications. Reference \& User Services Quarterly, 49 (1), 33-37, 51

[40] Langbauer, M., \& Lehner, F. (2015, October). An interactive video system for learning and knowledge management. In 2015 International Conference on Enterprise Systems (ES) (pp. 55-65). IEEE.

[41] Kleftodimos, A., \& Evangelidis, G. (2016). Using open source technologies and open internet resources for building an interactive video based learning environment that supports learning analytics. Smart Learning Environments, 3(1), 9.

[42] Chen, Y. T. (2012) A study on interactive video-based learning system for learning courseware. Research Journal of Applied Sciences, Engineering and Technology 4(20), 4132-4137.

[43] Mohamed A. K. (2003). Educational Technology Products, Dar Al-Hekma Library, Cairo.

[44] Salem, R. (2016). The effect of using interactive video on learning some skill and cognitive aspects of some rescue skills in swimming, The Scientific Journal of Physical Education and Sports, P (72) January, Egypt

[45] Abdel Ghaffar, S (2011). Measuring the Effectiveness of an Interactive Video Program for Learning a Mannequin Technique, Journal of Science and Arts, Studies and Research, Volume (12) p (1) January, Egypt.
[46] Al-Zabin, H. (2015). The Effect of Using the Flipped Learning Strategy on Academic Achievement of Female Students of the College of Education at Princess Noura Bint Abdulrahman University, The International Journal of Specialized Education, Vol. (3), P (1)

[47] Kolås, Line. (2015). Application of interactive videos in education. 10.1109/ITHET.2015.7218037.

[48] Preradovic, N. M., Lauc, T., \& Panev, I. (2020). Investigating interactivity in instructional video tutorials for an undergraduate informatics course. Issues in Educational Research, 30(1), 203.

[49] Jendoubi, A. (2017). Learning impact of interactive video in anesthesiology residency training: Preliminary study with TED-Ed platform. Saudi journal of anaesthesia, 11(3).

[50] Valerie J. Shute (2007). Focus on Formative Feedback. Research \& Development. March 2007 RR-07-11

[51] Khalil, H, A (2018). The effect of different patterns of providing feedback (informational - corrective explanatory) in an adaptive learning management system on developing the skills of producing electronic activities among students of the College of Education. Journal of Educational Technology: Studies and Research. P. 37, c. 1 .

[52] Muradni, M, \& Mukhtar, N, Q (2011). The effect of the interaction between the pattern of providing feedback within the virtual classroom and the level of mental capacity on the development of self-regulation skills and learning efficiency among educational technology learners, Journal of the College of Education, Al-Azhar University, 6 (146), 775-776

[53] Al-Zahrani, K. S. (2018). The effect of the difference of the feedback pattern (immediate-postponed) in cognitive trips on the development of achievement among first-year secondary school students at the Computer Course, International Journal of Educational and Psychological Sciences- Arab Foundation for Scientific Research and Human Development, (11).

[54] Al-Qat M., Abdel Samie, M., Jama H. and Abu Raya, W., (2014): The effect of providing automatic feedback in a web-based constructive environment in acquiring programming and motivation skills towards learning, Journal of Education, Studies and Research, April, Egypt.

[55] Omar, M. K. (2016). The effectiveness of a training program based on the use of the educational feedback strategy in increasing the expressive linguistic outcome of children with autism, Journal of Special Education and Rehabilitation- Special Education and Rehabilitation Institute, 3 (10).

[56] Thomson, DL (2010) Beyond the classroom walls: teachers' and students' perspectives on how online learning can meet the needs of gifted students. Journal of Advanced Academics 21: 662-712.

[57] Lorenzo, A. R., \& Lorenzo, B. U. (2013). Learning styles of teacher education students: Basis in improving the teaching-learning process. Procedia-Social and Behavioral Sciences, 103(2013), 595-605. 
[58] Al-Hawari, Jamal, Suleiman, Al-Sir (2013). The Effect of Learning Styles and Internal Motivation on Beyond Memory of a Sample of University Students, (30 (2) Arab Studies in Education and Psychology, Part Three, August, Saudi Arabia

[59] Griggs, S. A. (1984). Counseling the gifted and talented based on learning styles. Exceptional children, 50(5), 429432

[60]Zheng, M. F. \& Lin, S. H. (2010). Study of the relation of 5 th and 6th students' science learning style, motivation and achievement, Chinese Bioscience, 52, 39-56.

[61] Wang, P. X. (2007). Effect of learning style of undergraduates on achievement, China Journal of Health Psychology, 3, 226-229.

[62] Lu, X. B. (2013). A correlation study between junior school students' learning style and English score, Journal of the Chinese Society of Education, 12, 52-55.

[63] Ackerman, D. S., \& Hu, J. (2011). Effect of type of curriculum on educational outcomes and motivation among marketing students with different learning styles. Journal of Marketing Education, 33(3), 273-284.

[64] Cheong KFR, Tsui E. (2011). Exploring linkage between personal knowledge management and organizational learning. In Personal Knowledge Management: Individual, Organization and Social Perspectives, Pauleen D, Gorman G (eds.). Gower: Surrey, England

[65] Wright, K. (2005). Personal knowledge management: supporting individual knowledge worker performance. Knowledge management research \& practice, 3(3), 156-165.

[66] Vineta K., Sintija S., Dagnija D. (2016). ROLE OF PERSONAL KNOWLEDGE MANAGEMENT IN EEDUCATION TO ELIMINATE PLAGIARISM IN TERTIARY EDUCATION IN A COMPLEX WAY, 3rd International Multidisciplinary Scientific Conference on Social Sciences \& Arts SGEM, Section Education and Educational Research,

[67] Hosseingholizadeh, R., Sharif, A., \& Kouhsari, M. (2018). PKM Tools for Developing Personal Knowledge Management Skills among University Students. International Journal of Information Science and Management (IJISM), 16(1).

[68] Agnihotri, R., \& Troutt, M. D. (2009). The effective use of technology in personal knowledge management: A framework of skills, tools and user context. Online Information Review, 33(2), 329-342.

[69]Hsiao, E. (2019). Strategies to Support Personal Knowledge Management Using a Wiki Site in Online Courses. Journal of Educators Online, 16(1), n1.

[70] Hosseingholizadeh, R., Sharif, A., \& Kouhsari, M. (2018). PKM Tools for Developing Personal Knowledge Management Skills among University Students. International Journal of Information Science and Management (IJISM), 16(1).

[71] Fathizargaran, R. (2012). Personal Knowledge Management: An Analysis of Benefits and Challenges of Using Web 2.0 Technologies at the Individual Level. MA thesis, Victoria University of Wellington, New Zealand Retrieved from http://hdl.handle.net/10063/2620

[72] Avery S., Brooks, R., Brown, J., Dorsey, P., and O'Conner, M. (2001). Personal knowledge management: framework for integration and partnerships. In Proceedings of the 2001 ASCUE Summer Conference, P. Smith (ed.), (ed. P. Smith), North Myrtle Beach, South Carolina, 10-14, 39-43.

[73] Hertberg-Davis, H. L., \& Callahan, C. M. (2013). Introduction. In H. L. Hertberg-Davis \& C. M. Callahan (Eds.), Fundamentals of gifted education (1-10). New York, NY: Routledge

[74] Siegle, D. (2014). Technology: Differentiating instruction by flipping the classroom. Gifted Child Today, 37(1), 5155.

[75] Arnold-Garza, S. (2014). The flipped classroom: Assessing an innovative teaching model for effective and engaging library instruction. College \& Research Libraries News, 75(1), 10-13.

[76] Schultz, D., Duffield, S., Rasmussen, S. C., \& Wageman, J. (2014). Effects of the flipped classroom model on student performance for advanced placement high school chemistry students. Journal of chemical education, 91(9), 1334-1339.

[77]Correa, M. (2015). Flipping the foreign language classroom and critical pedagogies: a (new) old trend. Higher Education for the Future, 2(2), 114-125.

[78] Mattis, K. V. (2015). Flipped classroom versus traditional textbook instruction: Assessing accuracy and mental effort at different levels of mathematical complexity. Technology, Knowledge and Learning, 20(2), 231-248

[79] Blau, I., \& Shamir-Inbal, T. (2017). Re-designed flipped learning model in an academic course: The role of cocreation and co-regulation. Computers \& Education, 115, 69-81

[80] Afzal, S., \& Masroor, I. (2019). Flipped Classroom Model for Teaching Undergraduate Students in Radiology. Journal of the College of Physicians and Surgeons Pakistan, 29(11), 1083-1086.

[81] Reda I. S, (2016). The effect of using interactive video on learning some skill and cognitive aspects of some of the rescue skills in swimming, Scientific Journal of Physical Education and Sports, 76.

[82] Salman S. A. (2013). The effect of using interactive video in developing the skill of audio comprehension in the English language among middle school students, Master Thesis, College of Education, Al-Baha University, Saudi Arabia

[83] Snape, P. (2017). Enduring Learning: Integrating C21st Soft Skills through Technology Education. Design and Technology Education: An International Journal, 22(3), 48-59.

[84]Cheong, R. K., \& Tsui, E. (2011). From skills and competencies to outcome- based collaborative work: Tracking a decade's development of personal knowledge management (PKM) models. Knowledge and Process Management, 18(3), 175-193. 
[85] Al-Far, I. A (2012). Educations of Twenty-first Century Technology- Web Technology (2.0), Delta Computer Technology, Tanta.

[86] Sezer, B. (2017). The effectiveness of a technologyenhanced flipped science classroom. Journal of Educational Computing Research, 55(4), 471-494.

[87]ÇALIŞKAN, E., GÖKÇE, S., \& ÖNAL, N. (2019). Investigating the Usability of Interactive Videos with 3D Content for Developing Spatial Skills. Necatibey Faculty of Education Electronic Journal of Science \& Mathematics Education, 13(1).

[88]Hao, M., \& Fu, H. X. (2006). The correlation of performance in English proficiency test with multidimensional intelligence, learning style, and learning strategy. Foreign Language and Literature Studies, 90, 24, 235-243.

[89] Tempelman-Kluit, N. (2006). Multimedia learning theories and online instruction. College \& Research Libraries, 67(4), 364-369.

[90] Galster, M., Mitrovic, A., \& Gordon, M. (2018, May). Toward enhancing the training of software engineering students and professionals using active video watching. In Proceedings of the 40th international conference on software engineering: Software engineering education and training (5-8). Gothenburg: IEEE.

[91] Langbauer, M., \& Lehner, F. (2015, October). An interactive video system for learning and knowledge management. In 2015 International Conference on Enterprise Systems (ES) (pp. 55-65). IEEE.

[92] Dunn, R., Honigsfeld, A., Doolan, L. S., Bostrom, L., Russo, K., Schiering, M. S., \& Tenedero, H. (2009). Impact of learning-style instructional strategies on students' achievement and attitudes: Perceptions of educators in diverse institutions. The Clearing House: A Journal of educational strategies, issues and ideas, 82(3), 135-140. 